\title{
The influence of the processes of design and redesign of construction works on the performance of the production for the enterprises of building Industry
}

\author{
Petr Graboviy ${ }^{1, *}$ \\ ${ }^{1}$ Moscow State University of Civil Engineering, Yaroslavskoe shosse, 26, Moscow, 129337, Russia
}

\begin{abstract}
Design and redesign of construction works is a formal and informal specification relating to the actions of the individual, including both structural and interpersonal aspects of the work, taking into account the needs and demands of both the organization and the individual. The term "redesign of construction work" necessarily implies such operational approaches and methods as change of work, growing responsibilities, ergonomic factors, enrichment of work, the design of socio-technical systems, formation of teams performance/productivity, streamline production operations, etc. The systematic redesign of works usually use either methods related to the solution of employment problems on an individual basis, from time to time, or methods of diagnosis, evaluation and improvement of work organization in the framework of a larger program aimed at improving productivity and quality of working life. When "appropriate" task or problem set before "according" by a group or individuals and used "appropriate" group process, the results can be exceptional and serve as an effective source of productivity growth and efficiency of construction companies.
\end{abstract}

\section{Introduction}

In classic work "An Inquiry into the Nature and Causes of the Wealth of Nations" (1776) Adam Smith coined the term "division of labor" and described its advantages. The industrial revolution and the ensuing establishment of scientific management gave rise to the continuous specialization of labor. Analysis of methods of remuneration, simplification of operations, scientific organization of labor and some system of incentives - it was aimed at the study, analysis and design of more effective work. Since the beginning of the XX century until the early 40 -ies the main concern of management of various sectors of the economy was improving methods of production, including in the construction sector $[1,2]$.

In the late 1930's years, considerable attention began to attract research in the field of the relationship between man's place in the production system and specialization of labor. The first systematic attempts to redesign work on the part of management was in the scientific management, scientific organization, standardization and improvement of work

*Corresponding author: osun_kaf@mgsu.ru 
processes, operations research and ergonomic approaches. For example, in the early stages of the industrial revolution in the United States there have been several successful attempts to improve the efficiency of enterprises. But as the administration had violated human rights and were unable to apply these methods properly, they acquired undeservedly a bad reputation. Further abuse of named methods led in the late 30 -ies to the emergence of the concept of human relations.

In the postwar period in Western European countries gained the power of trade unions and approaches to the humanization of work.

The extension work was first targeted by the administration's attempt to move away from the trend towards specialization and standardization, typical of the turn of the century to the redesign of work.

Change of work is the first attempt to deal with boredom and dissatisfaction caused by excessive specialization. During the change of the work functions are changing. That may affect vertical and horizontal load of the employee. For example, a key element of the Japanese management style is, obviously, the horizontal change of work from function to function at all levels of the organization. This leads to a slowdown of the process of promotion, a deeper understanding of the relationships in the organization, and to improve cooperation and coordination. Change of work as a method of redesigning work does not enjoy sufficient popularity among Western European managers, but its skillful application of this approach, obviously, there are opportunities in improving efficiency in the long term $[3,4,5,6]$.

For the past 60 years there has been an intertwining of the concepts of human relations, scientific theories and management practices. Known independence of both approaches is preserved in our days, but at the same time, there is the development of integrated (hybrid) integrated management theories.

In the $70-90$-ies of the last century and the early 2000s have become more obvious the problems caused by the impact of dissatisfaction of workers with their performance. In all cases when the work or job change due to new technology, reorganization of the company, the employee, with indications of the management or process of management by objectives, we can talk about the redesign work. Description redesign can be formal or informal. A formal description is carried out in the form of specifications and characteristics of the works, as well as benchmarks [2,7].

An informal description that is often more important, is carried out in the framework of discussions with employees, peers or in order of initiative of the employee. Both formal and informal description help to define the way in which the individual uses to perform this work (Figure 1).

Support and regulation of development processes is a key task of regional public policy, having at their disposal a fairly wide range of instruments (Figure 1). 


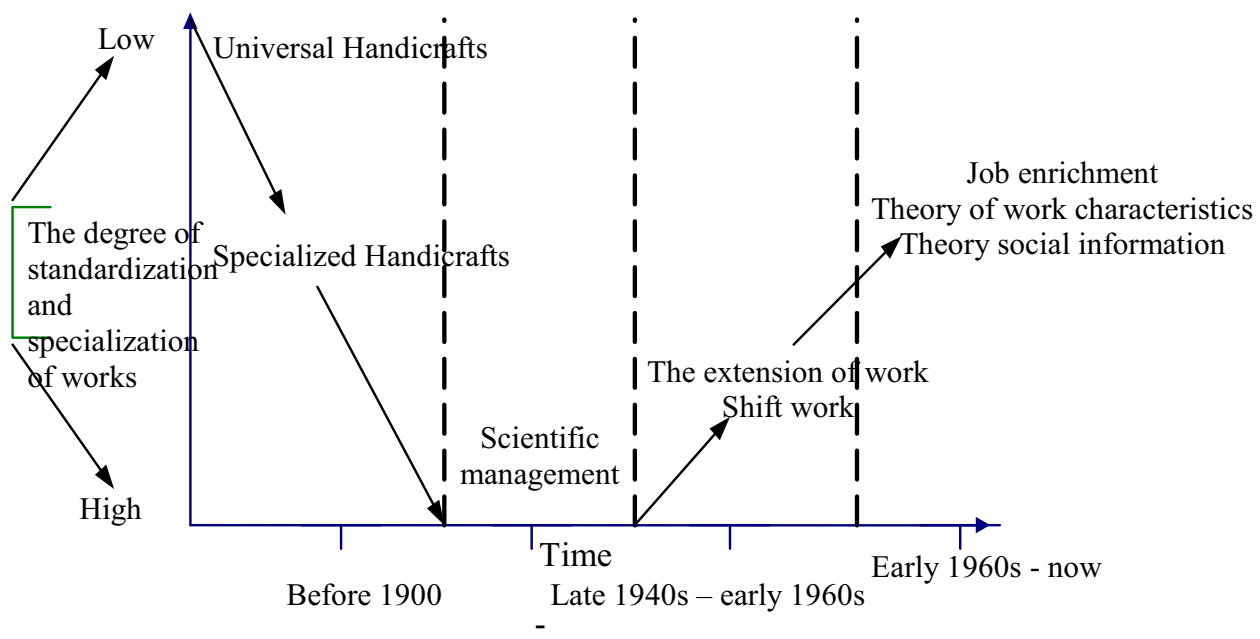

Fig. 1.The development of scientific performance management.

\section{System of Redesign of Construction Works}

Currently, priority for the development of investment-construction complex of Russia is the management of construction industry enterprises through the improvement of their performance attractiveness in terms of flexible planning using various modeling techniques, assess the features and capabilities of achieving goals and objectives, manage and plan full life cycle of finished construction products.

The enterprise of the construction industry can increase its performance by changing the internal environment, namely:

- production and economic activity (transition to the effective use of local raw materials base, process re-engineering range of finished construction products, expansion of assortment of building production);

- organization of work management (implementation of flexible management structures). the purpose of the redesign of work/job is to change (or interconnected system works) so that workers higher evaluated the quality of their working life, their motivation was stronger, and the actual performance (productivity, efficiency, quality, innovation) is higher.

The term "redesign of construction work" necessarily implies such operational approaches and methods as change of work, growing responsibilities, ergonomic factors, enrichment of work, the design of socio-technical systems, formation of teams performance/productivity, streamline production operations, etc. Although in this area are conducted a lot of research, however, to predict the effect of methods of redesigning work is hard $[8,9]$. The main difficulties associated with the study of this question for the construction companies, stem from the following points:

1. The presence of a large circle and the number of methods that you can use this approach;

2. The lack of specific applications for each method and therefore the possibility of its consistent use;

3. Intuitive approach to redesigning the activities (development and implementation of methods of diagnostics and estimation procedures behind the application of the methods themselves).

Therefore, there are no universally accepted criteria or performance measures of the companies by which to assess the quality of designing work. As mentioned above, there is no one strategy for improving project work. Most of the work is not designed to 
comprehensively and systematically from the beginning of their execution, and subjected to constant informal redesign.

The systematic redesign of works usually use either methods related to the solution of employment problems on an individual basis, from time to time, or methods of diagnosis, evaluation and improvement of work organization in the framework of a larger program aimed at improving productivity and quality of working life. The redesign of work differs from other approaches the science of behavior in four ways, so it is an excellent method of stimulating organizational change. First, redesign of works leads to a change in the fundamental relationship of the individual to his work. It can be argued that this is perhaps the most important relationship between the individual and the organization. Second, the changing nature of the expectations associated with labor, redesign directly affects behavior. Assuming that the job is accepted, you can expect that employee behavior will be focused on a new job. Third, in connection with the redesign of work often open a variety of opportunities to start other organizational changes. Diagnoses and procedures associated with many methods of redesign, often give some insight into the possibility of further changes that can positively affect individual and group performance. For example, in the programs of the redesign of work often emerge possible improvements in methods, technology, important relationships and interdependencies. Finally, fourth, the redesign of the works is capable in the long term to ensure a balance of public and human needs with the technological needs of the enterprises. Under "extension work" means a horizontal load on the worker, while the "enrichment work" is the vertical load. If you have in mind a hierarchical structure, e.g., secretaries, as a rule, lie in the same plane, and the function of the Manager in the other. To expand means to give the employee more work of the same type, whereas for the enrichment of the work entrusted to it "more difficult" and "higher order" work.

The simplification of the operation represents the opposite of expansion. It involves partitioning the work into its constituent elements or operations thus, in order to detect highly specialized technological operations, train them and then efficiently execute them.

Enrichment of labour constitutes the most common and probably the most successful approach to the redesign of work. Although in the development of instrumentation in this area this theory has proven fruitful, it has often been criticized for oversimplification and methodological shortcomings $[10,11]$.

The theory of enrichment of the work comes from the fact that meaningful work is characterized by at least the following six factors:

1. Responsibility: employee is responsible for the performance;

2. Achievement: employee believes that he has an important job;

3. Control over resources: the degree of employee control over the work being performed;

4. Feedback: the degree of employee obtaining direct information concerning the performance;

5. Professional growth: the degree of possibility for the employee to increase skills;

6 . Working conditions: the worker control over working conditions.

\section{The Theory of Characteristics of Works}

On the basis of earlier studies on the issue of design works has developed important new direction, referred to as the theory of characteristics of works. The fundamental model of this theory is shown in Figure 2. She claims that the probability of a positive psychological state of the individual is increased in the presence of five significant aspects of the work. Three of these aspects - diversity, completeness and relevance and link richness of the work. Let's consider them in more detail.

1. The variety of work means that it requires and allows for different-shaped actions 
involving different skills and aptitudes;

2. The finished work means that it requires and allows for the completion of the whole, and clearly distinguishable cycle the action or do the work from beginning to end with visible results;

3. Relevance describes the degree to which the employee is aware of its significant impact on organizational production system, the enterprise as a whole and perhaps even on the construction industry and society.

The other two aspects - autonomy and feedback.

The theory comes from the fact that all five of these aspects of work are the main points that determine the motivation and satisfaction of the employee. The degree to which manifest these important psychological factors, and determines, according to the theory, the probability that will be obtained favorable results in a personal and productive way. The model claims that the work, which is typically more named five aspects, will be more motivated and will bring more satisfaction than the work in which these aspects are inherent to a lesser degree.

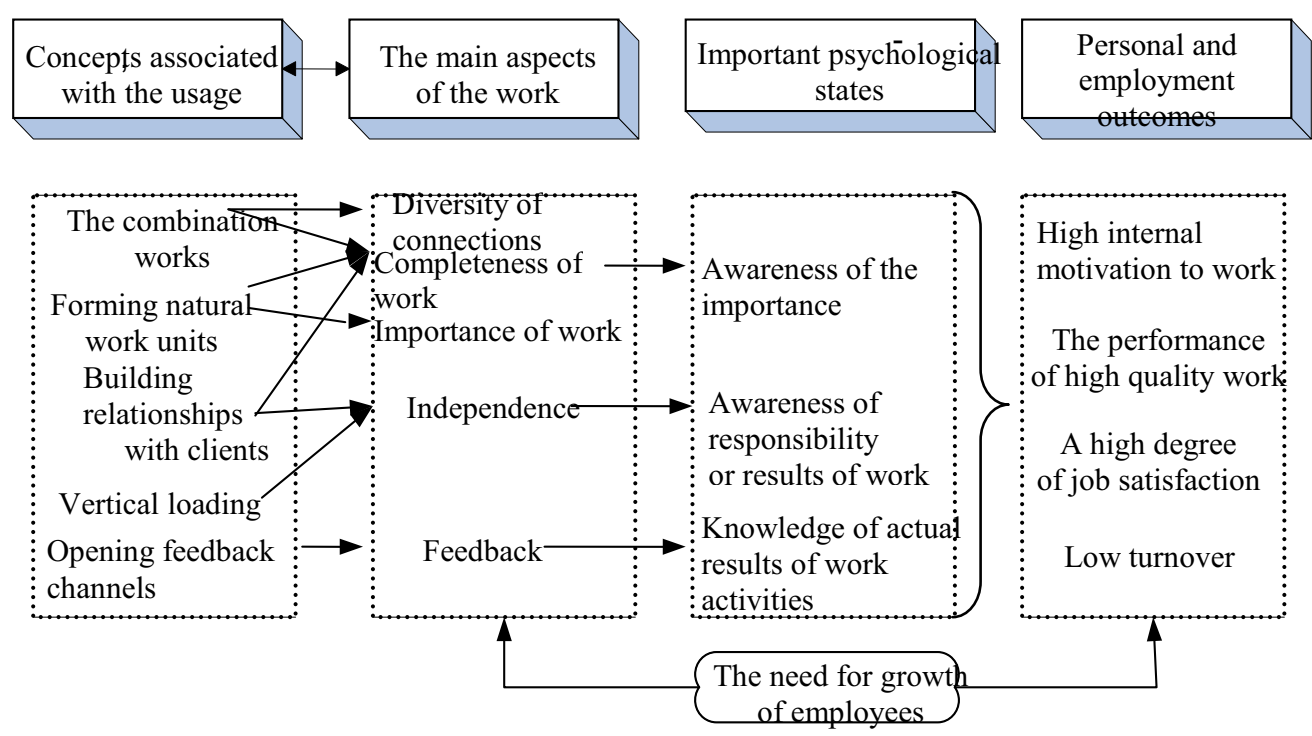

Fig.2.General model of the theory of characteristics of works.

The theory also recommends that the important variable governing the relationship between the characteristics (independent variable) and personal and production results (the dependent variable), namely the intensity of the needs of the worker in growth $[12,13]$.

To make a model of the operational characteristics it is primarily necessary to identify the reaction of employees (self-reports) on the characteristics of the work using tools such as diagnostic evaluation (DEW) and a list of items (LoI). Most often the dependent variable is job satisfaction (weak spot in this area of research), which are evaluated using such methods of analysis of work of installations as descriptive index (DIW), index of organizational reactions (IOR), questionnaire on satisfaction (QS) and the scale of job satisfaction (SJS). The most recent studies have explored the question of whether it is possible to differentiate between General measures used in the design of works (DEW and LoI), and measures of satisfaction with work (other treatments).

For example, using the DEW procedure to obtain an indicator of the motivational potential (IMP) combine the indicators relating to the five aspects of the work. Formula 
combining individual results to produce a single index of motivational potential is low IMP are potential candidates for redesign. In Figure 3 shows an example of a possible diagnosis using the DEW procedure. Once identified work to be redesign, the theory characteristics are used for this purpose on the basis of five basic principles.

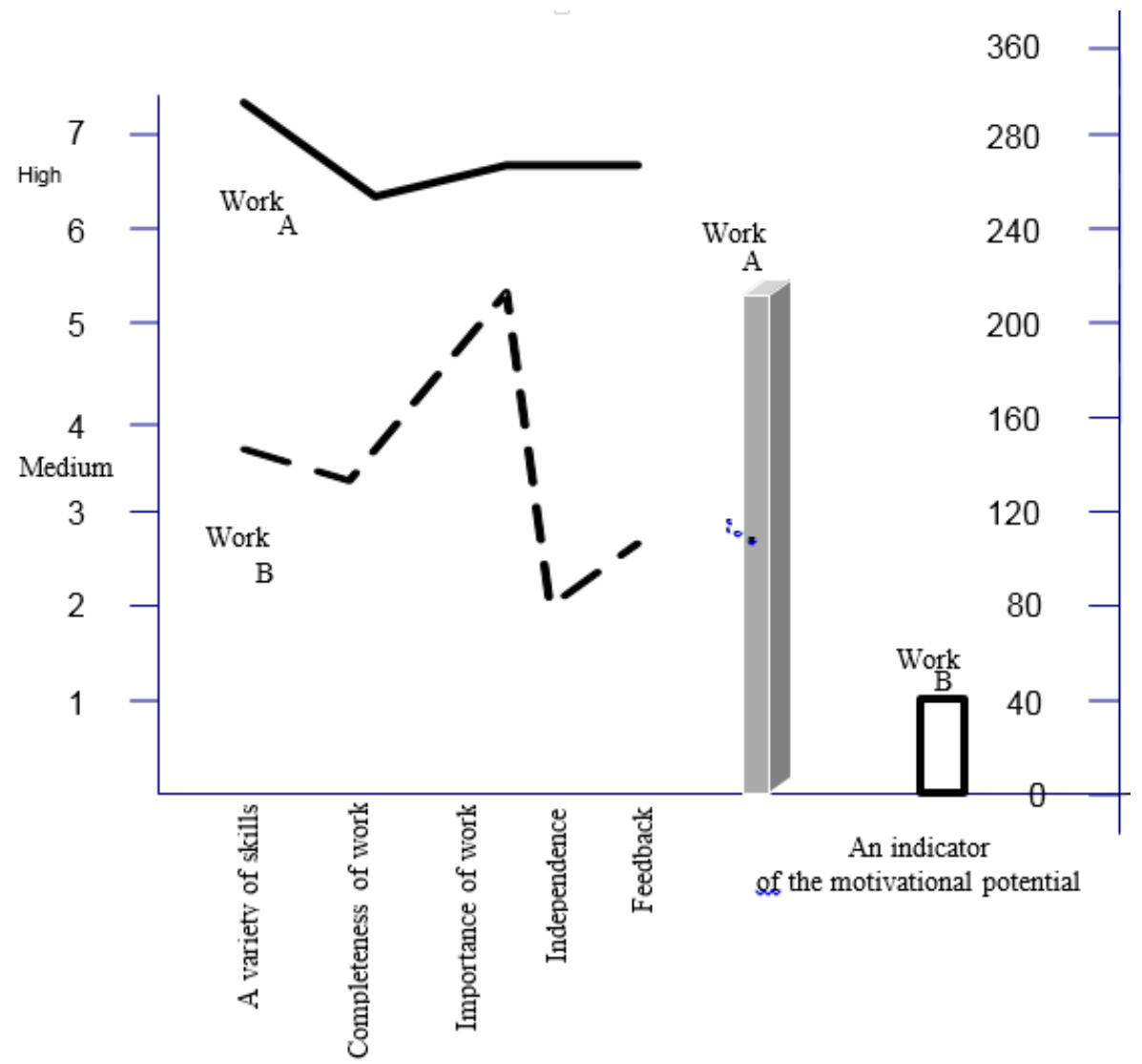

Fig. 3.Diagnostic review of the work: characteristics of "good" and "bad" work.

These principles include: the formation of natural units of labor, union of work, relationship-building, providing the vertical loading opening feedback channels.

In Figure 4 shows the relationship between the main aspects of the work and the listed principles of the changes. 


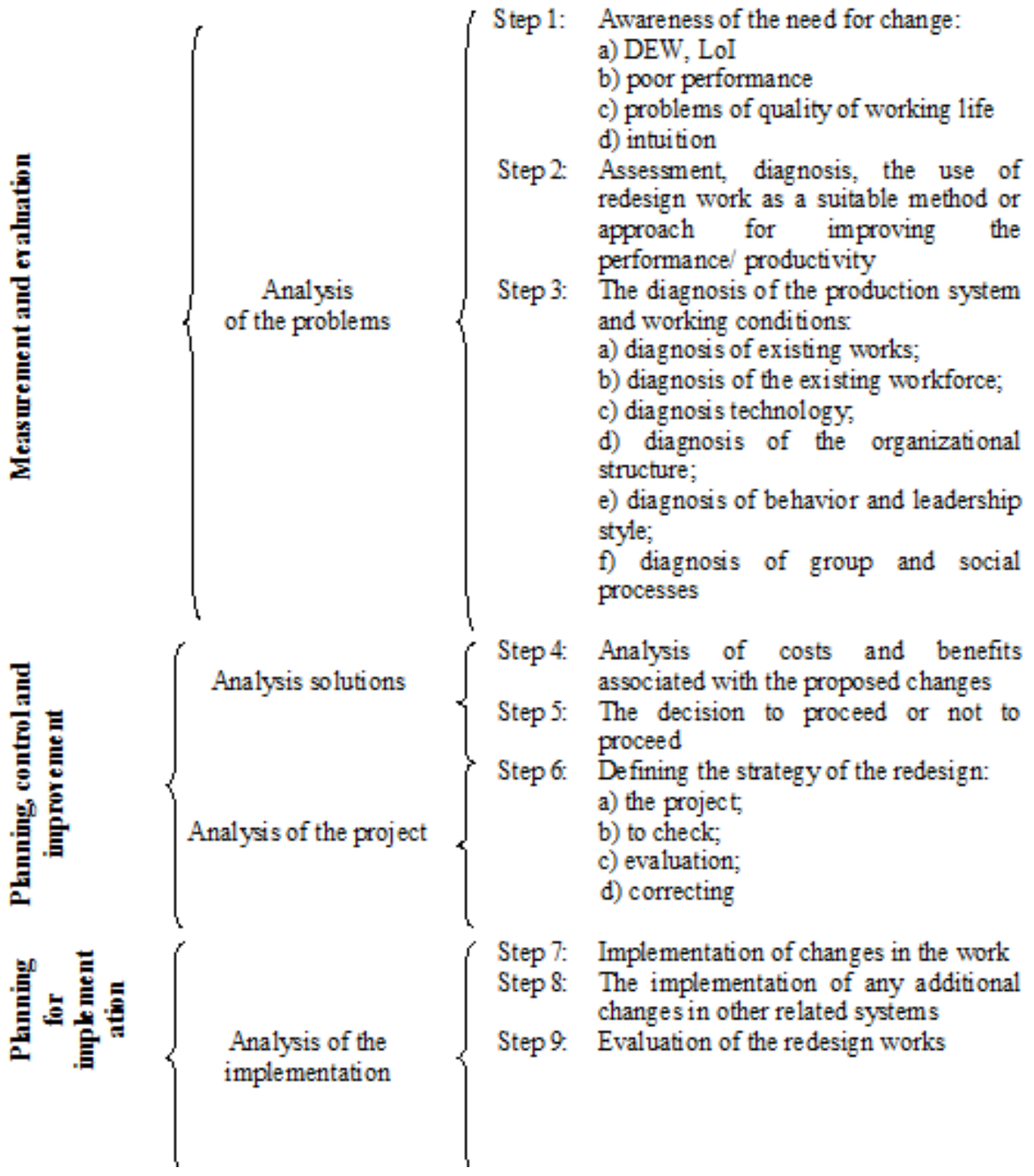

Fig. 4. The relationships between the main aspects of the work and principles of application.

\section{Diagnostic Evaluation of the Work}

Diagnostic evaluation (DEW) intended "for use as in case of the works before their redesign, and in research and evaluation of the impact of redesign work on those who perform them". As studies have shown, the whole procedure DEW includes more than 80 positions. Indicators on five major aspects of the work obtained by averaging the indicators for the three positions, and then based on the IMP calculates the index. Therefore, the advantage of the DEW is that begins to form the normative base for comparisons $[1,14,15$, $16]$.

In 2000-ies the strategy of involving employees becomes necessary, if not sufficient, element of any productivity programme. At the enterprises of the construction industry, especially industrial construction, maturity and expectations of employees rapidly 
increased. Currently, many workers, especially professionals of the construction industry, expect a certain degree of participation in solving problems related to work. In investment and construction projects, developed deliberately and systematically, this approach is increasingly seen as a process to increase the probability of effective and economical use of other methods to increase performance. Consent and a tendency to accept, support and even suggest some positive changes in the area of improving performance that can be achieved through properly designed participatory programs, seen as essential prerequisites for the survival of most businesses in the coming decades in accordance with the decision of the state Council of the Russian Federation from 28.05.2016 "On the development of construction and improvement of urban development in the Russian Federation" $[17,18]$.

It therefore seems that the principle of employee participation is appropriate to put the following questions:

1. Why use participatory strategies and methods?

2. When to use a participatory approach or method?

3. What form of participatory approach should be used?

4. Who should be involved in the process?

5. What should they aim for the participation of employees (e.g., solving problems, developing solution procedures, clarifying problems, making decisions)?

6. How to incorporate participatory approach or method into the broader program to improve performance?

7. How to properly manage the participatory approach, method or program to ensure their success?

The solution consists of the following sequence, shown in Figure 5.
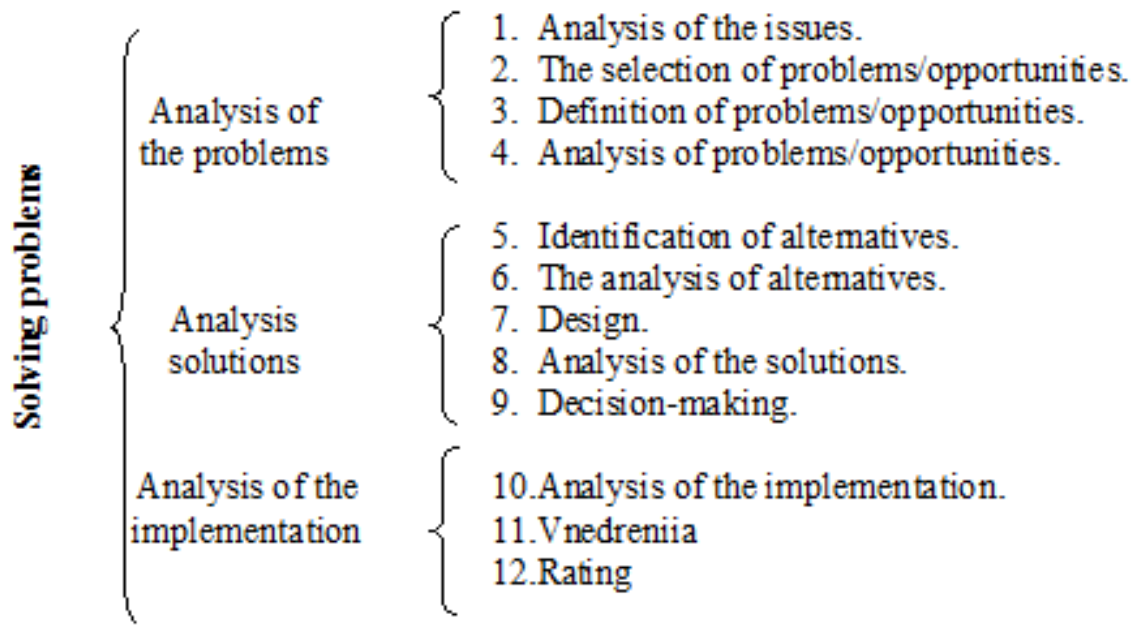

Fig. 5.The procedure of solving problems.

Further, the involvement of employees often requires also the activity of small groups relating to one or more of the 12 listed activities.

The involvement or participation of workers should:

1) be carried out effectively and economically;

2) affect the "proper" workers on "proper" work;

3) instill an understanding of the need for change;

4) provide efficient and cost-effective decisions on how, what and where to implement the changes;

5) provide awareness on the part of employees and groups in the area of change; 
6) promote positive changes;

7) ensure the compatibility of the goals of the individual, groups and organizations;

8) give scope to the energy and abilities of people;

9) provide a more efficient, faster and overall smoother implementation;

10) promote the professional development of workers;

11)improve communication, cooperation and coordination;

12)inspire commitment;

13)improve the work unit;

14)improve the quality of work;

15)ensure greater group harmony;

16)lead to the highest possible performance;

17)result in the highest possible overall performance.

When participatory programs and recruitment methods are properly designed and integrated with organizational and managerial processes, they are able to lead to many of the above results. Any method or approach, whatever its merits and applicability may fail or even result in negative effects if it is misapplied. This is particularly true in relation to the methods of the science of behavior and social Sciences, as their successful use largely depends on the skills of those who resort to them. As a result, many attempts fail, and labour morality seriously undermined.

The involvement and participation of workers increasingly means:

1) voice in solving problems;

2) consultation, seeking consent;

3) acceptance of the final decision;

4) deliberate, systematic attempt to identify and use individual and collective wisdom;

5) shared decision making;

6) effective delegation;

7) joint identification of problems and appropriate action;

8) ability to create appropriate environments and settings;

9) mechanism to improve the cooperation of workers and management.

Involvement and participation are increasingly seen as a necessary but not sufficient elements of the productivity programme.

\section{Conclusion}

Managers in the construction industry, as other industries have resorted to participatory strategies for the following reasons:

- increases the maturity of the employees (their ability and willingness to work);

- becoming more popular and expedient to delegate to the subordinate units, to resort to decentralization of responsibility related to decision-making in organizations;

- strategies enhance the effectiveness of implemented decisions (the Japanese take decisions more slowly, but they are much better implement decisions);

- strategies provide a better understanding of the decisions and challenges of their implementation;

- increase the awareness and skill that can be required, the group and the individuals in future jobs;

- provide the ability groups, organizational systems, and organizations to solve problems in a proactive and productive manner;

- frequently create a mechanism for the growth of employees and supervisors, as well as improve the communication at this important level;

- able to improve and often improve communication and cooperation between departments and services. A vital internal communication channels often represent a complex problem 
in the field of efficiency and productivity, and it can be solved by using properly designed programs of employee participation;

- pave the way for necessary innovation in organizational systems.

When "appropriate" task or problem set before "according" by a group or individuals and used "appropriate" group process, the results can be exceptional and serve as an effective source of productivity growth and efficiency of construction companies.

\section{References}

1. A.M. Krygina, L.V. Sevryukova, Industrial and civil construction8, 36-39(2011)

2. Real Estate construction and housing and utilities sector of Russia(VNIINTPI, Moscow, 2013)

3. A.H. Bizhanov, The Scientific basis of the choice of organizational methods of management with processes of urban reconstruction and renovation of residential buildings(MGSU, Moscow, 2005)

4. V.V. Bredikhin,Economics, management,1(2011)

5. E.A. Gusakova, A.S. Pavlov, Tutorial and workshop for undergraduate and graduate programs(Urait,Moscow,2016)

6. N.P. Shepelev, M.S. Shumilov, Reconstruction of urban development(Higher school,Moscow, 2000)

7. P.G. Graboviy, Organizational-technological system module surveying(ASV,Moscow,2015)

8. V.V. Bredikhin,Economics, management,1(2011)

9. I.I. Mazur, V.D. Shapiro, Management of investment-construction projects: an international approach(Omega-L,Moscow, 2009)

10. P.G. Graboviy, Risks in modern business(Illuminator,Moscow, 2017)

11. P.G. Graboviy, The construction of the unique facilities of the transportation system for the Olympic Sochi(Frontier, Sochi, 2014)

12. V.K. Ivanets, V.S. Reznichenko, A.V. Bogdanov,Managing projects and businesses in the construction industry(Slovo, Moscow, 2001)

13. M.I. Kowalski,Construction Management: experience of USA, Japan, UK, Germany, Canada(Stroiizdat,Moscow, 1994)

14. E.A. Gusakova,Vestnik MGSU1, 358-361 (2008)

15. O. Kaplinski, Procedia Engineering 57, 533-539 (2013)

16. S. Asgari, R. Awwad, A. Kandil, I. Odeh, Automation in Construction 65, 9-20 (2016)

17. M. Nový, J. Nováková, M. Bartoš, Procedia Engineering 161, 759-764 (2016)

18. V.Y. Ostashko, Life-cycle management of enterprises investment-construction complex: theory and practice(DIA,Moscow, 2003) 